\title{
PROSTHESIS REPAIR VERSUS BIOLOGICAL TISSUE REPAIR FOR PRIMARY INGUINAL HERNIA TREATMENT
}

\author{
Anbalagan Poongavanam ${ }^{1}$, Srikanth $R^{2}$, Arunkumar $A^{3}$, Balakrishnan $R^{4}$ \\ ${ }_{1}^{1}$ Associate Professor, Department of General Surgery, Government Tiruvannamalai Medical College and Hospital, Tiruvannamalai, \\ Tamilnadu, India. \\ 2Associate Professor, Department of General Surgery, Government Tiruvannamalai Medical College and Hospital, Tiruvannamalai, \\ Tamilnadu, India. \\ 3Junior Resident, Department of General Surgery, Government Tiruvannamalai Medical College and Hospital, Tiruvannamalai, \\ Tamilnadu, India. \\ 4Junior Resident, Department of General Surgery, Government Tiruvannamalai Medical College and Hospital, Tiruvannamalai, \\ Tamilnadu, India.
}

\begin{tabular}{l}
\hline ABSTRACT \\
\hline BACKGROUND \\
As per various Hernia societies, the tissue repair for Hernia stands old and gold standard till now. ${ }^{[1]}$ The various tissue repairs we \\
routinely practice are Shouldice technique, modified Bassini's procedure ${ }^{[2]}$ and recent years Desarda's technique in our study \\
conducted between $2017-18$. Randomised clinical trial for prosthesis repair, Lichtenstein Hernioplasty versus tissue based repair \\
Desarda's procedure were selected.[3]
\end{tabular}

\section{MATERIALS AND METHODS}

A total of 102 male patients were randomly assigned to Desarda's and Lichtenstein repair. Out of this, 51 patients underwent Desarda's and 51 patients underwent Lichtenstein procedure. The variable factors considered under this study were postoperative seroma at wound site, post-operative pain, duration of surgery and post-operative recovery to daily routine activity on 7 , 14 and 30 post-operative day and recurrence.

\section{RESULTS}

During the study, the time consumed for performing both procedures were equal. Post-operative seroma developed in 2 patients who underwent mesh repair, post-operative pain in 3 patients of Desarda's and 5 patients of mesh repair. Post-operative recovery was good in both the study groups and no recurrence was found during study period in both the groups.

\section{CONCLUSION}

As per study of comparison between mesh repair and tissue repair during study period of one year, the cost of mesh was negligible in Desarda's procedure and Desarda's procedure needs technical experience and gives good outcome when compared to Lichtenstein repair.[4]

\section{KEY WORDS}

Desarda's Procedure, Lichtenstein Repair Seroma, Post-Operative Pain.

HOW TO CITE THIS ARTICLE: Poongavanam A, Srikanth R, Arunkumar A, et al. Prosthesis repair versus biological tissue repair for primary inguinal hernia treatment. J. Evolution Med. Dent. Sci. 2018;7(42):4497-4500, DOI: 10.14260/jemds/2018/1003

\section{BACKGROUND}

A randomised controlled trial study of Inguinal Hernia remains an important surgical problem in both males and females. The risk of development of inguinal hernia is higher in males around $25-28 \%$, but in females it comes around less than $5 \%$. The various surgical method practiced worldwide, the European Hernia Society recommended certain guidelines to be followed in Hernia surgery such as mesh repair by open or laparoscopic technique.[5] But still the nomesh technique, shouldice plays an important role. The mesh commonly used can create problems like seroma formation, post-operative pain and discomfort in groin which may persist for weeks to months.

'Financial or Other Competing Interest': None.

Submission 08-08-2018, Peer Review 29-09-2018,

Acceptance 05-10-2018, Published 15-10-2018.

Corresponding Author:

Dr. Srikanth R,

73-GPM Street, Gudiyatham,

Gudiyatham TK. Vellore Dt.-632602, Tamilnadu, India.

E-mail: srirangalya@gmail.com

DOI: $10.14260 /$ jemds $/ 2018 / 1003$
In laparoscopic procedure, the recurrence rate and mesh migration is high and some studies report sexual discomfort in post hernia mesh repair.[6] To overcome this problem nonmesh hernia repair becomes famous such as Desarda's method, which was introduced in 2001.[7]

\section{MATERIALS AND METHODS}

The randomised controlled trial study was conducted in patient of age around 35 - 60 years unilateral indirect hernia alone taken for study. Only non-diabetic and nonhypertensive patient without any other co-morbidities were selected. The patient not willing to participate was excluded from the study. The study period of around 1 year, conducted in Department of General Surgery, Govt. Thiruvannamalai Medical College, Thiruvannamalai District, Tamilnadu. Randomised clinical trial followed for total 102 patients, 51 underwent Lichtenstein repair and 51 underwent Desarda's technique. All patients willing for study with selection criteria were taken for study during study period only in our institution. A total of 102 patient's sample size was taken for convenience. 


\section{Randomisation}

The purpose and protocol of the study was explained to the patients. The subjects consented to participate were randomly divided into two groups using a computergenerated random number table: 1) Patients who underwent Lichtenstein repair; 2) Patients who underwent Desarda's technique. The allocations were concealed in consecutively numbered and sealed envelopes.

\section{Procedure}

The follow-up period around one year. The protocol formed such as all these patients underwent surgery in spinal anaesthesia[ ${ }^{[8]}$ with single dose of antimicrobial one hour prior to surgery, same company mesh used for patients who underwent Lichtenstein hernioplasty.[9] The mesh fixed with 1 prolene to pubic tubercle, inguinal ligament and conjoint tendon.

After the inguinal canal had been opened, the hernias were described using the Gilbert-Modified Robbins-Rutkow classification system as follows-

1. Type 1, indirect hernia with normal internal ring;

2. Type 2 , indirect hernia with internal ring enlarged but $<4$ $\mathrm{cm}$;

3. Type 3 , indirect hernia with internal ring enlarged $>4 \mathrm{~cm}$;

4. Type 4, direct hernia with destroyed posterior wall of the inguinal canal;

5. Type 5, direct hernia with defect next to the pubic tubercle;

6. Type 6, pantaloon hernia;

7. Type 7, femoral hernia. For both techniques, the skin was closed with continuous non-absorbable suture. Patients were encouraged to resume normal activities as soon as possible.[10]

Desarda's method: - The undetached aponeurotic strip is created and displaced from the anterior to posterior wall of the inguinal canal.[11] It was then secured to the abdominal internal oblique muscle with interrupted sutures and to the inguinal ligament. The follow-up inpatients were examined by a blinded investigator until discharge and seen during follow-up at 3, 7 and 30 days after surgery. The appointments on day 7 were performed during the patients' visits to outpatient surgical departments and the follow-up appointments after day 7 were performed in the departments' examination rooms. Both the patients and controlling investigators were blinded to the hernia surgery method used. The investigator who was performing the follow-up physical examinations and patient assessments was a surgeon in each department who did not perform the surgeries in this study. The recurrences and other complications were recorded. Pain was measured using a Visual Analog Scale (VAS), which ranged from 0 (no pain) to 100 (maximum, unbearable pain).

Additionally, Pain was recorded with the use of the Sheffield Scale-

- 0, no pain;

- 1 , no pain at rest but it appears during movement;

- 2, temporary pain at rest and moderate during movement;

- 3 , constant pain at rest and severe during movements.
Return to normal activity was described as the patient's ability to perform elementary activities [i.e. dressing, walking, bathing (Basic activity); usual activities at home [i.e. preparing food, cleaning house (home activity) and returning to all previously performed activities (work activity). The aim of the present study was to compare that the Desarda's repair is as effective as the standard Lichtenstein procedure, allowing successful hernia repair without mesh. The primary outcomes were duration of surgery performed, hernia recurrence and chronic pain, defined as moderate (VAS 3054) or strong (VAS 54) pain lasting more than 6 months after surgery. The secondary outcomes were general and local complications like seroma formation,[12] length of time to return to various levels of everyday activity, foreign body sensation and abdominal wall stiffness in the groin area. Some of basic characters including demographics, comorbidities and occupation were similar in the two groups. Hernia are indirect unilateral hernia, reducible without any complication. Intraoperative procedure standardised for both Desarda's and Lichtenstein procedure, ${ }^{[13]}$ such as Herniotomy and strengthening posterior wall of inguinal canal. Of the 102 patients operated on, all were examined at the 3, 7, 14-day and 30-day in one year follow-up visits. Afterward two patients who underwent Lichtenstein repair developed seroma collection at operated site on third postoperative day (4\%), but no patient underwent Desarda's procedure developed seroma ( $0 \%)$. The post-operative pain reported by 3 patients in Desarda's (6\%) and 5 patients reported in Lichtenstein repair $(10 \%)$, but the mild analgesics relieved the pain within 7 days and made them to recover early to routine activities. There were no recurrence reported in both Desarda's and Lichtenstein procedure. No patients reported foreign body sensation, abdominal wall stiffness and subjective loss or change in sensation in the operated groin.

\section{Statistical Analysis}

The SPSS software was used for statistical analysis. The data underwent descriptive analysis to determine the frequency, percentage, mean and standard deviation. Chi-square and student t-test were used to compare qualitative and quantitative variables, respectively, between the two groups of Bassini and Lichtenstein. P-value less than 0.0001 was considered as significant.

\section{RESULTS}

\begin{tabular}{|c|c|c|c|c|c|c|c|}
\hline \multirow{4}{*}{\begin{tabular}{|r}
$\begin{array}{r}\text { Sl } \\
\text { No }\end{array}$ \\
1.
\end{tabular}} & \multirow{2}{*}{$\begin{array}{c}\text { Variables } \\
\text { Total } \\
\text { Operated }\end{array}$} & \multirow{4}{*}{ 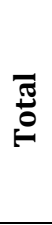 } & \multirow{4}{*}{ 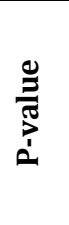 } & \multicolumn{2}{|c|}{$\begin{array}{c}\text { Lichtenstein } \\
\text { Procedure }\end{array}$} & \multicolumn{2}{|c|}{$\begin{array}{l}\text { Desarda's } \\
\text { Procedure }\end{array}$} \\
\hline & & & & 51 & $\%$ & 51 & $\%$ \\
\hline & Direct hernia & & & 39 & $78 \%$ & 27 & $57 \%$ \\
\hline & Indirect hernia & & & 12 & $22 \%$ & 24 & $43 \%$ \\
\hline 2. & Seroma & 2 & .99 & 2 & $4 \%$ & 0 & $0 \%$ \\
\hline 3. & $\begin{array}{c}\text { Post-operative } \\
\text { pain }\end{array}$ & 8 & .99 & 5 & $10 \%$ & 3 & $6 \%$ \\
\hline 4. & Recurrence & $\mathbf{0}$ & - & 0 & $0 \%$ & 0 & $0 \%$ \\
\hline 5. & $\begin{array}{l}\text { Foreign body } \\
\text { sensation }\end{array}$ & 0 & - & 0 & $0 \%$ & 0 & $0 \%$ \\
\hline 6. & \multicolumn{3}{|c|}{ Duration of surgery mean } & \multicolumn{2}{|c|}{$\begin{array}{l}75 \text { minutes }+- \\
5 \mathrm{mts}\end{array}$} & \multicolumn{2}{|c|}{$\begin{array}{l}65 \text { minutes }+- \\
5 \mathrm{mts}\end{array}$} \\
\hline & \multicolumn{7}{|c|}{$\begin{array}{c}\text { Table 1. Data Outcome comparable with Statistical } \\
\text { Tabular Column }\end{array}$} \\
\hline
\end{tabular}

$\mathrm{P}$ value $>0.0001$ 


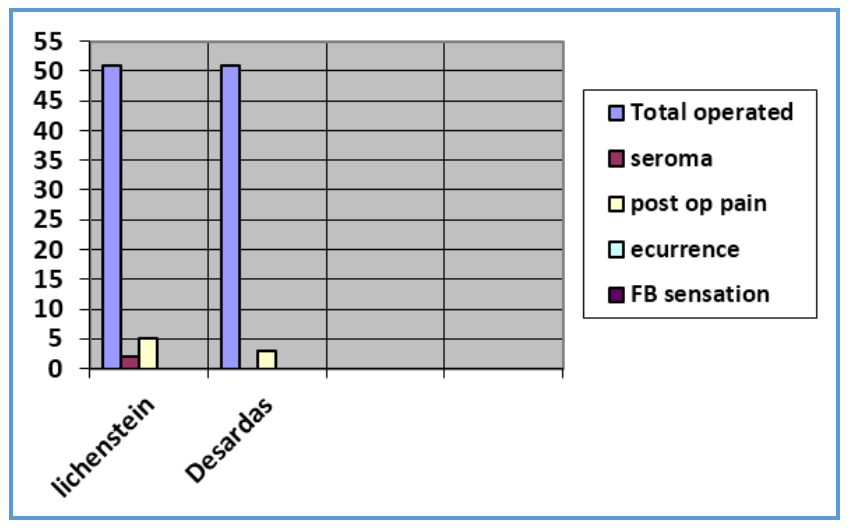

\begin{tabular}{|c|c|c|}
\hline \multirow{2}{*}{ Group } & \multicolumn{2}{|c|}{ Seroma Formation } \\
\cline { 2 - 3 } & Yes & No \\
\hline Desarda's & 2 & 0 \\
\hline Lichtenstein & 5 & 3 \\
\hline \multicolumn{2}{|c|}{ Table 2 } \\
\hline
\end{tabular}

P value $>0.0001$

\section{DISCUSSION}

The present study, direct hernia $78 \%$ and indirect in $22 \%$ in Lichtenstein group and $57 \%$ direct and $43 \%$ indirect in Desarda's group. The P value is 0.17 , which showing both the groups are comparable. The incidence of direct inguinal hernia is more in our study. This distribution varied from other studies with indirect type being most common. More than $2 / 3^{\text {rd }}$ of patients have indirect type of hernia. However, there is no absolute correlation regarding this variable in all the studies overall. Inguinal hernias are more common on right side. The cause may be because of delayed descent of the right testicle. The present study shows $64.3 \%$ right, $35.7 \%$ left hernia in Lichtenstein group and $60.72 \%$ right and $39.28 \%$ left hernia in Desarda's group. The P values are not significant. Both the groups are comparable and the results are similar to the literature. The mean duration of the total surgery in Lichtenstein group was $75 \pm 5$ mins, while that in Desarda's group was $65 \pm 5$ mins. There was a statistically significant difference of nearly 10 minutes with a $\mathrm{P}$ value > 0.0001. On POD 1 the mean VAS score in Lichtenstein group was 5, while that in Desarda's group was 4, though the difference is small it is still statistically significant with a $\mathrm{P}$ value $>0.0001$.

No recurrence in inguinal hernia was seen in patients of both the Lichtenstein and Desarda groups during the 6 months follow-up period. No significant differences in clinical outcomes were observed during a 1-year follow-up of adult male patients with a primary inguinal hernia operated on with either the Desarda or the Lichtenstein technique.[14] Seroma formation, the frequency of complications was similar for the two groups with little difference. Outcomes and post-operative complications by operative method. Results are the median and range unless otherwise stated. The mean recurrence rate for the standard Lichtenstein procedure is about $1 \%$ in hernia specialised centres, but can be much higher in community hospitals (about 4\%) and the reported rate even reaches $18 \%$ in some articles. The data published so far for other mesh techniques vary: 0 to $4.2 \%$ recurrences for Prolene Hernia System (PHS), 0 to $4 \%$ for Rutkow, 1.6 to $19.0 \%$ for the Transabdominal Pre-Peritoneal inguinal hernia repair (TAPP). The summarised frequency of postoperative complications reported in the available literature is between 15 and $28 \%$. When active postoperative monitoring is applied, the frequency can even reach 50\%.[15] The most frequently reported complications were haematoma, seroma, surgical-site infection, chronic pain and recurrence.[16] Death and major worsening of the treated patients' quality of life were rare, but also reported. Commercially available lightweight polypropylene meshes, composed meshes and many biologic prostheses are being tested. The scientific work of optimising hernia surgery and lowering the number of complications is still in progress. The Desarda technique for inguinal hernia repair is a new tissuebased method. Despite the objections presented by some authors, application of the external oblique muscle aponeurosis in the form of an undetached strip (which makes the posterior wall of the inguinal canal stronger) has been established as a new concept in tissue based hernia repair. The aponeurotic strip is displaced from the anterior to the posterior wall of the inguinal canal without additional tension at the posterior wall. Collagen metabolism manifested by a decreased type I: III collagen ratio. The Shouldice technique, which is still recommended and accepted worldwide, is tissue-based as well. To date, there has been no comparison study on the aponeurotic tissue and the transversalis fascia. The properties of inguinal connective tissue are being generalised mainly from studies on the transversalis fascia. In our study, there were no statistically significant differences between the patients enrolled and randomised to the Desarda and Lichtenstein groups. The recurrence rate was the same in both groups. Although, chronic pain has been defined as lasting 3 months by the International Association for the Study of Pain, we defined chronic pain as pain lasting 6 months due to the use of synthetic materials for the hernia repair and taking into account the fact that the inflammatory response to foreign material may last longer.[17] This approach has been used by many other authors and is recommended in the latest publications.[18] At the early postoperative time points ( 7 and 30 days), after the VAS scale was transferred to a descriptive scale (Verbal Rating Scale, VRS) no differences at any of the follow-up time points including at 6 months were observed. The percentage of other early and late complications was comparable. The higher ratio of seromas, infection after use of the Lichtenstein method can be explained by the influence of the synthetic mesh on surrounding tissues.[19] This is consistent with other studies and the known influence of polypropylene on tissue. Foreign body sensation and abdominal wall stiffness were expressed by 12 to $16 \%$ of the Desarda group patients and 17 to $22 \%$ of the Lichtenstein group patients at different time points and the results are within the range (4.5 - 43.8\%) reported by other authors for mesh techniques. To the best of our knowledge, this is the first report of a randomised clinical trial comparing the Desarda and Lichtenstein techniques in our institution. Other results, published by Desarda and his group, were based on a comparison of his technique and the Lichtenstein technique. They reported no recurrence among the 269 Desarda group patients and $1.97 \%$ recurrence among the 225 mesh group patients; $6.49 \%$ of patients from the mesh group and no patients in the Desarda group reported chronic pain at 1 year after surgery. Paradoxically, in the modern world, the cost of the medical treatment becomes the real issue. One indisputable advantage of Desarda technique is its low cost. That is why many published articles recently 
demonstrated an interest in the technique. The cost of the Desarda operation is low because a synthetic prosthesis is not needed. The price of composite meshes or even heavy polypropylene meshes, as well as their accessibility, could be important issues in developing countries. We confirmed that even the inguinoscrotal hernias (Rutkow types 3, 4 and 6), which are frequently seen can be successfully treated with the Desarda technique.[20] Economic issues are not the only considerations. The use of synthetic material is still controversial in young patients. The effect of polypropylene placement or other synthetic mesh inside human organism for a lifetime. Also, data are appearing about sexual impairment after mesh implantation and as a result many surgeons try to avoid mesh prosthesis for hernia treatment in young patients. Also, the Desarda method, a tissue-based technique, can be used in a contaminated surgical field, usually seen during operations for strangulated hernias.

\section{CONCLUSION}

The study of comparison of Desarda's versus Lichtenstein mesh repair confirmed that both the procedures hold standard for inguinal hernia repair during the study period of one year. Only the tissue-based repair such as Desarda's needs technical experience, otherwise it consumes time. Since in Desarda's no mesh is used, the cost of procedure is much reduced. Patients who are allergic to mesh repair and disagree for mesh repair can undergo Desarda's repair.

\section{REFERENCES}

[1] Simons MP, Aufenacker T, Bay-Nielsen M, et al. European Hernia Society guidelines on the treatment of inguinal hernia in adult patients. Hernia 2009;13(4):343-403.

[2] Ravitch MM, Hitzrot JM 2nd. The operations for inguinal hernia. I. Bassini, Halsted, Andrews, Ferguson. Surgery 1960;48:439-66.

[3] Mitura K, Romanczuk M. Comparison between two methods of inguinal hernia surgery-Lichtenstein and Desarda. Pol Merkur Lekarski 2008;24(143):392-5.

[4] Szopinski J, Kapala A, Prywinski S, et al. Desarda technique for inguinal hernia treatment: first polish experiences. Pol Przegl Chir 2005;77:159-68.

[5] Jeans S, Williams GL, Stephenson BM. Migration after open mesh plug inguinal hernioplasty: a review of the literature. Am Surg 2007;73(3):207-9.

[6] Schmedt CG, Sauerland S, Bittner R. Comparison of endoscopic procedures vs Lichtenstein and other open mesh techniques for inguinal hernia repair: a metaanalysis of randomized controlled trials. Surg Endosc 2005;19(2):188-99.
[7] Desarda MP. New method of inguinal hernia repair: a new solution. ANZ J Surg 2001;71(4):241-4.

[8] Bay-Nielsen M, Kehlet H. Anaesthesia and postoperative morbidity after elective groin hernia repair: a nation-wide study. Acta Anaesthesiol Scand 2008;52(2):169-74.

[9] Primatesta P, Goldacre MJ. Inguinal hernia repair:incidence of elective and emergency surgery, readmission and mortality. Int $\mathrm{J}$ Epidemiol 1996;25(4):835-9.

[10] Amid PK. Lichtenstein tension-free hernioplasty: its inception, evolution and principles. Hernia 2004;8(1):1-7.

[11] Desarda MP. Inguinal herniorrhaphy with an undetached strip of external oblique aponeurosis: a new approach used in 400 patients. Eur J Surg 2001;167(6):443-8.

[12] McRoy LL. Plugoma and the prolene hernia system. J Am Coll Surg 2011;212(3):424 author reply 424-5.

[13] Bay-Nielsen M, Kehlet H, Strand L, et al. Quality assessment of 26, 304 herniorrhaphies in Denmark: a prospective nationwide study. Lancet 2001;358(9288):1124-8.

[14] Adamonis W, Witkowski P, Smietanski M, et al. Is there a need for a mesh plug in inguinal hernia repair? Randomized, prospective study of the use of Hertra 1 mesh compared to PerFix Plug. Hernia 2006;10(3):223-8.

[15] Losanoff JE, Millis JM. Aponeurosis instead of prosthetic mesh for inguinal hernia repair: neither physiological nor new. Hernia 2006;10(2):198-9 author reply 200-2.

[16] Robinson TN, Clarke JH, Schoen J, et al. Major meshrelated complications following hernia repair: events reported to the Food and Drug Administration. Surg Endosc 2005;19(12):1556-60.

[17] D'Amore L, Gossetti F, Vermeil V, et al. Long-term discomfort after plug and patch hernioplasty. Hernia 2008;12(4):445-6.

[18] Hasegawa S, Yoshikawa T, Yamamoto Y, et al. Longterm outcome after hernia repair with the prolene hernia system. Surg Today 2006;36(12):1058-62.

[19] Genc V, Ensari C, Ergul Z, et al. A very late-onset deep infection after prosthetic inguinal hernia repair. Chirurgia (Bucur) 2010;105(4):555-7.

[20] Losanoff JE, Richman BW, Jones JW. Inguinal herniorrhaphy with an undetached strip of external oblique aponeurosis: old or new? Eur J Surg 2001;167(11):877. 